\title{
ANALISIS KELENGKAPAN PENGISIAN REKAM MEDIS PADA POLIKLINIK RAWAT JALAN BEDAH DI RS PERTAMINA BINTANG AMIN
}

\author{
Dwi Robbiardy Eksa ${ }^{1}$, Neno Fitriyani Hasbie ${ }^{2}$, Achmad Farich ${ }^{3}$, Dinda Ayu \\ Pratiwi $^{4}$ \\ 1,2,3Dosen Fakultas Kedokteran Universitas Malahayati \\ ${ }^{4}$ Program Pendidikan Dokter Fakultas Kedokteran Universitas Malahayati \\ email korespondensi: Dindaayupratiwi621@yahoo.com
}

\section{ABSTRACT: ANALYSIS OF COMPLETENESS OF MEDICAL RECORDING IN THE POLYCLINIC OF SURGICAL AT THE PERTAMINA BINTANG AMIN}

Backrgound: Medical records contain all information about patients, illness, medications and records in it recording to the order of service / care. There are still some an inadequate medical records. This happens because of the short time factor, the levels of doctor's knowledge, and human resources.

Purpose: this study was to determine the frequency distribution of completing medical record filling in outpatient surgical polyclinics at Pertamina Bintang Amin Hospital in 2019.

Method: This type of research is a descriptive study with a cross sectional approach. Regarding the analysis of the completeness of filling in medical records, the research subject was an outpatients surgical polyclinic at Pertamina Bintang Amin Hospital in 2019. The research time was August-October 2020 with a sample of 400 medical records.

Result: It was found that $73,5 \%$ outpatient surgical medical records were completely filled, $9,5 \%$ less complete and $17 \%$ incomplete. The frequency distribution of the components of completing medical record filling consisted of $98,75 \%$ complete and 1,25\% incomplete identify, complete date and time $90 \%$ and $1 \%$ incomplete, history $94,25 \%$ complete and $5,75 \%$ incomplete, the result of physical and supporting examinations $87,5 \%$ complete and $12,5 \%$ incomplete, diagnosis $97,5 \%$ complete and $2,5 \%$ incomplete, treatment or action $94,74 \%$ complete and $5,26 \%$ incomplete, other services provided to patients $83,5 \%$ are complete and $16,5 \%$ incomplete, consent to action if necessary $88,75 \%$ complete and $11,25 \%$ incomplete. Ant the frequency distribution of components that are considered less complete is the filling of the management plan $76,26 \%$, all anesthesia during pre and post surgery $79,5 \%$, all surgery reports (pathology and postoperative progress notes) $79,75 \%$, all reports of recorvery room $66,75 \%$. The frequency distribution of completing medical record filling in outpatient surgical polyclinics at Pertamina Bintang Amin Hospital is 73,5\% completely filled, 9,5\% less complete, and $17 \%$ complete.

Conslusion: This shows that the result of completingthe filling of medical records at the outpatient surgical clinic at Bintang Amin Hospital are still less complete.

Keywords: Completeness, Medical Record, Surgical Polyclinic 


\section{INTISARI: ANALISIS KELENGKAPAN PENGISIAN REKAM MEDIS PADA POLIKLINIK RAWAT JALAN BEDAH DI RUMAH SAKIT PERTAMINA BINTANG AMIN}

Pendahuluan: Rekam medis berisi semua informasi mengenai pasien, penyakit, pengobatan dan rekaman yang didalamnya sesuai dengan urutan pelayanan/perawatan. Masih ditemukan beberapa rekam medis yang tidak memenuhi syarat. Hal tersebut terjadi karena beberapa faktor waktu yang singkat, tingkat pengetahuan dokter dan sumber daya manusia.

Tujuan: penelitian ini bertujuan untuk mengetahui distribusi frekuensi kelengkapan pengisian rekam medis pada poliklinik rawat jalan bedah di Rumah Sakit Pertamina Bintang Amin Tahun 2019.

Metode: Jenis penelitian ini adalah penelitian deskriptif dengan pendekatan cross sectional. Mengenai analisis kelengkapan pengisian rekam medis, dengan subjek penelitian adalah poliklinik rawat jalan bedah di Rumah Sakit Pertamina Bintang Amin Tahun 2019 dengan jumlah sampel rekam medis sebanyak 400. Hasil: Didapatkan kelengkapan rekam medis poliklinik rawat jalan bedah sebanyak 73,5\% terisi lengkap, 9,5\% kurang lengkap dan 17\% tidak lengkap. Distribusi frekuensi kelengkapan pengisian rekam medis poliklinik rawat jalan bedah di Rumah Sakit Pertamina Bintang Amin tahun 2019 tertinggi terdapat pada komponen tanggal dan waktu yaitu $99 \%$ lengkap dan komponen terendah terdapat pada semua laporan ruang pemulihan (recovery room) yaitu 66,75\%. Distribusi frekuensi kelengkapan rekam medis poliklinik rawat jalan bedah di Rumah Sakit Pertamina Bintang Amin sebanyak 73,5\% terisi lengkap, 9,5\% kurang lengkap dan $17 \%$ tidak terisi lengkap.

Kesimpulan: Hal ini menunjukkan hasil kelengkapan pengisian rekam medis pada poliklinik rawat jalan bedah Rumah Sakit Bintang Amin masih kurang lengkap.

Kata Kunci : Kelengkapan, Rekam Medis, Rawat Jalan Bedah

\section{PENDAHULUAN}

Peningkatan mutu sistem pelayanan kesehatan dan pelayanan medik yang baik harus dilakukan seiring dengan kemajuan teknologi informasi, hal ini disebabkan karena pada sistem pelayanan kesehatan dan medik yang diutamakan dalam profesi kedokteran adalah etik kedokteran dan masalah yang akan timbul nantinya pada etik kedokteran tersebut. Profesi kedokteran merupakan pekerjaan yang berhubungan dengan kedokteran yang didasarkan oleh suatu keilmuan, kemampuan yang didapatkan melalui pendidikan berjenjang, serta kode etik yang bersifat melayani masyarakat (Undang-Undang Republik Indonesia Nomor 29 Tahun 2004).
Seorang dokter dalam praktik kedokteran wajib memberi pelayanan medis yang baik dan sesuai dengan standar agar masyarakat mendapatkan pelayanan medis yang sesuai dan profesional. Dalam hal ini membuat rekam medis setelah pasien selesai menerima pelayanan kesehatan adalah salah satu kewajiban seorang dokter (Undang-Undang Republik Indonesia Nomor 29 Tahun 2004).

Menurut World Health Organization (WHO), rumah sakit adalah bagian integral dari suatu organisasi sosial dan kesehatan dengan fungsi menyediakan pelayanan paripurna (komprehensif), penyembuhan penyakit (kuratif) dan pencegahan penyakit (preventif) kepada masyarakat (Bustani dkk, 2015). 
Berdasarkan Peraturan Menteri Kesehatan Nomor 56 Tahun 2014 tentang Klasifikasi dan Perizinan Rumah Sakit, pengelompokan rumah sakit berdasarkan penyelenggaraan, yaitu rumah sakit pemerintah, rumah sakit pemerintah daerah, dan rumah sakit swasta. Rumah sakit pemerintah adalah unit pelaksana teknis dari instansi pemerintah (Kementerian Kesehatan, Kepolisian, Tentara Nasional Indonesia, dan BUMN/Kementerian Lainnya). Rumah sakit daerah adalah pelaksana teknis dari daerah (pemerintah provinsi, pemerintah kabupaten dan pemerintah kota). Sedangkan rumah sakit swasta adalah badan hukum yang kegiatan usahanya hanya bergerak di bidang perumahsakitan, pengecualian bagi Rumah Sakit Publik yang diselenggarakan oleh badan hukum yang bersifat nirlaba. Rumah sakit di Indonesia dari tahun 2014-2018 mengalami peningkatan sebesar 16,92\%. Pada tahun 2014 jumlah rumah sakit sebanyak 2.406 meningkat menjadi 2.813 pada tahun 2018. Jumlah rumah sakit di Indonesia sampai dengan tahun 2018 terdiri dari 2.269 Rumah Sakit Umum (RSU) dan 554 Rumah Sakit Khusus (RSK). (Rachma, A.N, dkk, 2019).

Provinsi Lampung mempunyai 30 unit rumah sakit yang tersebar diseluruh kabupaten dan kota, dimana jumlah rumah sakit yang terbanyak terdapat di Kota Bandar Lampung yaitu berjumlah 21 unit. Dengan adanya 21 unit rumah sakit yang tersebar di Kota Bandar Lampung ini, sangat membantu masyarakat dalam mendapatkan pelayanan kesehatan yang baik. Hal ini karena jumlah penduduk di Kota Bandar Lampung merupakan yang terpadat dan merupakan pusat jasa, perdagangan dan perekonomian di Provinsi Lampung, sehingga memerlukan pelayanan kesehatan yang banyak (Sari NA, 2018).

Pelayanan pasien di rumah sakit dibagi menjadi dua area, yaitu pelayanan rawat jalan (poliklinik) untuk pasien non-gawat darurat dan pelayanan instalasi gawat darurat untuk pasien yang mengalami kegawatdaruratan. Pelayanan Rawat Jalan adalah pelayanan pasien untuk observasi, diagnosis, pengobatan, rehabilitasi medik dan pelayanan kesehatan lainya tanpa menginap di Rumah Sakit (Kemenkes, 2007). Menurut International Federation Health Record Organization (IFHRO) rekam medis adalah a health record contains all information about a patient, his illness and treatment and the end entries in it are recorded in the order in which event of care occurs (rekam medis berisi semua informasi mengenai pasien, penyakit, pengobatan dan rekaman yang didalamnya sesuai dengan urutan pelayanan/perawatan) (Lubis AN, 2009).

Berdasarkan Permenkes No. 269/MENKES/PER/III/2008, ringkasan pulang (resume) harus dibuat oleh dokter atau dokter gigi yang melakulan perawatan pada pasien. Isi ringkasan pulang sekurang-kurangnya memuat: identitas pasien; diagnosa masuk dan indikasi pasien dirawat; ringkasan hasil pemeriksaan fisik dan penunjang, diagnosa akhir, pengobatan dan tindak lanjut; nama dan tanda tangan dokter atau dokter gigi yang memberikan pelayanan kesehatan.

Ketidakterisian pada rekam medis dapat disebabkan oleh banyak faktor, salah satunya adalah ketidakterisian diagnosis pada lembar ringkasan klinik karena dokter lebih mengutamakan memberikan pelayanan, banyaknya pasien sehingga dokter berusaha memberikan pelayanan dengan 
cepat, dokter masih menunggu hasil pemeriksaan laboratorium untuk lebih memastikan diagnosis yang lebih spesifik, waktu yang singkat, dan tingkat pengetahuan dokter, (Herisa DC, 2017).

Kelengkapan pengisian rekam

medis dapat dipengaruhi oleh beberapa faktor, antara lain: (1) latar belakang pendidikan tenaga kesehatan, (2) masa kerja, (3) pengetahuan mengenai rekam medis (manfaat, kegunaan, pertanggungjawaban), (4) kete rampilan, (5) motivasi, (6) alat kerja, (7) sarana kerja, (8) waktu kerja, (9) pedoman tertulis, (10) kepatuhan terhadap pedoman (Erfavira A, dkk, 2012).

Setiap sarana kesehatan wajib membuat rekam medis baik instalasi rawat jalan, instalasi rawat inap, maupun instalasi gawat darurat. Kelengkapan berkas rekam medis merupakan laporan penting untuk perlindungan hukum tenaga medis. Pencatatan pengisian berkas rekam medis yang lengkap dapat membantu dalam pengambilan keputusan tentang terapi, tindakan, dan penentuan diagnosis pada setiap pasien (Hatta, 2011). Kualitas kelengkapan isi rekam medis kasus bedah harus diperhatikan karena dapat dipergunakan sebagai bahan penilaian oleh staf medis dalam menjamin kelanjutan pelayanan medis yang berkualitas dan

\section{METODE PENELITIAN}

Pengambilan sampel akan dilakukan dengan cara simple random sampling. Setelah sampel dari poliklinik rawat jalan bedah ditetapkan berdasarkan periode yang telah ditentukan, dilakukan pengumpulan data rekam medis. Setelah data rekam medis terkumpul, kemudian data-data dari hasil pengumpulan data rekam medis dianalisis peningkatan mutu pelayanan rumah sakit.

Setiap sarana juga memiliki prosedur yang berbeda. Berdasarkan hasil presurvey di Rumah Sakit Pertamina Bintang Amin tahun 20172018 didapatkan kelengkapan data rekam medis rawat jalan. Pada tahun 2017, diperoleh rekam medis rawat jalan sebanyak 56.401 , terdiri dari 54.996 (97\%) rekam medis lengkap dan 1.435 (3\%) rekam medis tidak lengkap. Rekam medis rawat jalan tahun 2018 diperoleh sebanyak 57.623, terdiri dari 55.642 (96\%) rekam medis lengkap dan 1.981 (4\%) rekam medis tidak lengkap.

Penelitian ini sejalan dengan penelitian sebelumnya di Rumah Sakit Pertamina Bintang Amin Tahun 2018 oleh Wulandari, dkk. Dalam penelitiannya didapatkan hasil perhitungan kelengkapan identifikasi pasien sebesar $53,5 \%$ dan $46,5 \%$ tidak lengkap. Sedangkan kelengkapan laporan yang penting sebesar $68,5 \%$ dan 31,5\% tidak lengkap yang dilihat dari identitas, diagnosa, tindakan, alternatif atau pelayanan lain yang telah diberikan dan persetujuan tindakan. Sehingga pada penelitian yang dilakukan oleh Wulandari, dkk tersebut dapat disimpulkan untuk presentase lengkap pada kelengkapan rekam medis bedah lebih besar daripada presentase tidak lengkap.

kelengkapan datanya. Kemudian akan diolah lebih lanjut.

Menurut Komisi Etik Penelitian Kesehatan Universitas Malahayati dengan nomor surat 1146/EC/KEP-UNMAL/VIII/2020, penelitian dengan judul Analisis Kelengkapan Pengisian Rekam Medis Pada Poliklinik Rawat Jalan Bedah Di Rumah Sakit Pertamina Bintang Amin Tahun 2019 dinyatakan laik etik. 
Design penelitian observasional yang digunakan adalah cross sectional dengan data yang digunakan adalah data sekunder, yaitu peneliti melakukan observasi kelengkapan pengisian rekam medis poliklinik rawat jalan bedah dan adanya faktor yang menjadi faktor risiko (independen) dan faktor efek (dependen) dimana pengukuran variabel bebas dan variabel terikat yang dinilai.

Populasi dalam penelitian ini yakni rekam medis diseluruh poliklinik rawat jalan bedah di Rumah Sakit Pertamina Bintang Amin tahun 2019 sebanyak 17.382. Sampel yang diambil dalam penelitian ini adalah rekam medis poliklinik rawat jalan bedah di Rumah Sakit Pertamina Bintang Amin Tahun 2019 dengan jumlah 400.

Pengambilan jumlah responden dalam penelitian ini akan dicari berdasarkan perhitungan rumus slovin :

\section{Analisis Univariat}

1. Distribusi Kelengkapan Rekam Medis

Distribusi kelengkapan rekam medis di Rumah Sakit Pertamina Bintang Amin, Bandar lampung ditampilkan dalam tabel berikut ini:

Tabel 1 distribusi Frekuensi Kelengkapan Rekam Medis Bedah

\begin{tabular}{ccc}
\hline Rekam Medis & Frekuensi & Persentase \\
\hline Lengkap & 294 & $73,5 \%$ \\
Kurang Lengkap & 38 & $9,5 \%$ \\
\hline Tidak Lengkap & 68 & $17 \%$ \\
\hline Total & 400 & $100 \%$ \\
\hline
\end{tabular}

Pada Tabel 1 diketahui bahwa distribusi frekuensi kelengkapan rekam medis di Rumah Sakit Pertamina Bintang Amin Bandar

Lampung, dari 400 sampel terdapat $73,5 \%$ rekam medis terisi lengkap, 9,5\% lengkap dan 17\% tidak lengkap.

2. Distribusi Kelengkapan Rekam Medis Berdasarkan Komponen Lembar Rekam Medis
Keterangan :

- ukuran populasi

e :Presentase kelonggaran ketidaktelitian karena kesalahan contoh yang masih dapat ditolerir (pada penelitian ini ditetapkan $5 \%)$.contoh yang masih dapat ditolerir pengambilan sampel akan dilakukan dengan cara simple random sampling. sampel dari poliklinik rawat bedah ditetapkan berdasarkan medis. Setelah data rekam medis terkumpul, kemudian data-data dari hasil pengumpulan data rekam medis dianalisis kelengkapan datanya. Kemudian akan diolah lebih lanjut. 
Tabel 2 Distribusi Frekuensi Kelengkapan Rekam Medis Berdasarkan Komponen Lembar Rekam Medis

\begin{tabular}{|c|c|c|c|c|}
\hline \multirow[t]{2}{*}{ Rekam Medis } & \multirow[t]{2}{*}{ Komponen } & \multicolumn{3}{|c|}{ Persentase } \\
\hline & & $\begin{array}{c}\text { Lengkap } \\
\text { (\%) }\end{array}$ & $\begin{array}{c}\text { Kurang } \\
\text { Lengkap } \\
(\%) \\
\end{array}$ & $\begin{array}{c}\text { Tidak } \\
\text { Lengkap } \\
(\%)\end{array}$ \\
\hline 1. Identitas & $\begin{array}{l}\text { a.Nama } \\
\text { b.Tanggal Lahir } \\
\text { c.Jenis Kelamin } \\
\text { d.Nomor Rekam Medis }\end{array}$ & 97,5 & 1,25 & 1,25 \\
\hline $\begin{array}{l}\text { 2. Tanggal dan } \\
\text { Waktu }\end{array}$ & & 99 & 0,5 & 0,5 \\
\hline 3. Anamnesis & $\begin{array}{l}\text { a.Keluhan dan Riwayat } \\
\text { Penyakit Sekarang } \\
\text { b.Riwayat Penyakit } \\
\text { Terdahulu } \\
\text { c.Riwayat Penyakit } \\
\text { Keluarga \& Sosial }\end{array}$ & 94,25 & 3,75 & 2 \\
\hline $\begin{array}{l}\text { 4. Hasil } \\
\text { Pemeriksaan } \\
\text { Fisik dan } \\
\text { Penunjang } \\
\text { Medis }\end{array}$ & & 87,5 & 8,75 & 3,75 \\
\hline 5. Diagnosis & $\begin{array}{l}\text { Kesimpulan dari } \\
\text { Anamnesa dan } \\
\text { Pemeriksaan Fisik }\end{array}$ & 97,5 & 1,25 & 1,25 \\
\hline $\begin{array}{l}\text { 6. Rencana } \\
\text { Penatalaksana } \\
\text { an }\end{array}$ & $\begin{array}{l}\text { Rencana Pengobatan, } \\
\text { Perawatan dan } \\
\text { Tindakan yang akan } \\
\text { Dilakukan. Seperti : } \\
\text { a. Tirah Baring } \\
\text { b. Posisi Setengah } \\
\text { Duduk } \\
\text { c. Pemasangan } \\
\text { Venflon } \\
\text { d. Pemasangan NGT, } \\
\text { O2 Masker } 6 \text { Liter } \\
\text { Permenit }\end{array}$ & 4,5 & 76,25 & 19,25 \\
\hline $\begin{array}{l}\text { 7. Pengobatan/ } \\
\text { Tindakan }\end{array}$ & $\begin{array}{l}\text { Rencana Pengobatan, } \\
\text { Perawatan dan } \\
\text { Tindakan yang akan } \\
\text { Dllakukan. Seperti : } \\
\text { a. Tirah Baring } \\
\text { b. Posisi Setengah } \\
\text { Duduk } \\
\text { c. Pemasangan Venflon } \\
\text { d. Pemasangan NGT, } \\
\text { O2 Masker } 6 \text { Liter } \\
\text { Permenit }\end{array}$ & 94,7 & 3,25 & 5,25 \\
\hline
\end{tabular}




\begin{tabular}{|c|c|c|c|c|}
\hline $\begin{array}{l}\text { 8. Pelayanan } \\
\text { Lain Yang } \\
\text { Telah } \\
\text { Diberikan }\end{array}$ & $\begin{array}{l}\text { Pemeriksaan Penunjang } \\
\text { Seperti : } \\
\text { Hasil Laboratorium }\end{array}$ & $83,5 \%$ & 4,25 & 12,25 \\
\hline $\begin{array}{l}\text { 9.Persetujuan } \\
\text { Tindakan }\end{array}$ & $\begin{array}{l}\text { Diperlukan Apabila Ada } \\
\text { Tindakan Yang } \\
\text { Memerlukan Tindakan } \\
\text { atau Operasi }\end{array}$ & 88,75 & 5,75 & 5,5 \\
\hline $\begin{array}{l}\text { 10. Anastesi (Pra } \\
\text { \& Pasca } \\
\text { Operasi) }\end{array}$ & & 8,5 & 79,5 & 12 \\
\hline $\begin{array}{l}\text { 11.Semua } \\
\text { Laporan } \\
\text { Operasi } \\
\text { (Catatan } \\
\text { Pasca } \\
\text { Operasi) }\end{array}$ & & 12,5 & 79,75 & 7,75 \\
\hline $\begin{array}{l}\text { 12.Semua } \\
\text { Laporan } \\
\text { Ruang } \\
\text { Pemulihan } \\
\text { (Recovery } \\
\text { Room) }\end{array}$ & & 5,25 & 66,75 & 28 \\
\hline Total & & $100 \%$ & $100 \%$ & $100 \%$ \\
\hline
\end{tabular}

Berdasarkan hasil penelitian, diketahui bahwa pada komponen distribusi frekuensi kelengkapan pengisian rekam medis bedah didapatkan presentase kelengkapan pengisian rekam medis paling tinggi yaitu terdapat di komponen tanggal dan waktu sebanyak (99\%), komponen identitas sebanyak (975\%) dan komponen diagnosa sebanyak (97,5\%). Sedangkan presentase kelengkapan pengisian rekam medis paling rendah yaitu pada komponen laporan ruang pemulihan (Recovery Room) (66,75\%). Padahal laporan ruang pemulihan

\section{KESIMPULAN DAN SARAN Kesimpulan}

1. Diketahui distribusi rekam medis poliklinik rawat jalan bedah di Rumah Sakit Pertamina Bintang Amin sebanyak $73,5 \%$ terisi lengkap, 9,5\% kurang lengkap dan 17\% tidak terisi lengkap.
(Recovery Room) dianggap cukup penting untuk melihat perkembangan pasien setelah operasi. Komponen lain yang masih kurang diperhatikan dalam pengisian adalah rencana penatalaksanaan sebanyak (76,25\%), semua anastesi saat pra dan pasca operasi sebanyak (79,5\%), semua laporan operasi (patologi dan catatan perkembangan pasca operasi) sebanyak (79,75\%). Pada KLPCM (Kelengkapan Laporan Pengisian Catatan Medis) yang dilakukan setiap bulan oleh unit rekam medis kepada management Rumah Sakit Pertamina. 
rekam medis poliklinik rawat jalan bedah yaitu komponen laporan ruang pemulihan (recovery room) $(66,75 \%)$.

\section{Saran}

Sebaiknya dalam pencatatan data sosial nama dan alamat pasien, penulisannya secara benar dan lengkap karena penulisan nama dan alamat sangat penting dan

\section{DAFTAR PUSTAKA}

Kemenkes, RI. (2004). UU RI No. 29 Tahun 2004 Tentang Praktik Kedokteran.

Indonesia, R. (2014). Peraturan Menteri Kesehatan No. 56 Tahun 2014 Tentang Klasifikasi dan Perizinan Rumah Sakit.

Indonesia, R. (2008). Peraturan Menteri Kesehatan Nomor 269/Menkes/Per/III/2008 Tentang Rekam Medis.

Pemerintah, R.I. (2004). UndangUndang Nomor 29 Tahun 2004 tentang Praktik Kedokteran. Jakarta: Republik Indonesia.

Pemerintah, R.I. (2009). UndangUndang Republik Indonesia Nomor 44 Tahun 2009 Tentang Rumah Sakit. Jakarta: Pemerintah RI.

Permenkes. (2018). Peraturan Menteri Kesehatan Republik Indonesia Nomor 4 Tentang Kewajiban Rumah Sakit Dan Kewajiban Pasien.

Departemen Kesehatan Republik Indonesia. (2017). Pedoman Teknis Sarana Dan Prasarana Rumah Sakit Kelas $C$.

Bustani, N.M., Rattu, A.J.,\& Saerang, J.S. (2015). Analisis Lama Waktu Tunggu Pelayanan Pasien Rawat Jalan Di Balai Kesehatan Mata Masyarakat Propinsi Sulawesi

Utara. eBiomedik, 3(3).

Rachma, A.N., dkk. (2019). Analisis Indrustri Pelayanan Kesehatan berpengaruh terhadap pencarian dokumen rekam medis.

Pada review pelaporan, lakukan pengisian dengan lengkap mengenai kegiatan yang dilakukan setiap profesional pemberi asuhan (PPA) yang mengisi rekam medis dengan jelas agar didapat informasi yang berkesinambungan serta dapat dipertanggungjawabkan.

Dunia Dan Indonesia (Rumah Sakit Siloam \& Rumah Sakit Mayapada). Surabaya. Universitas Bina Nusantara.

Sari, A.N. (2018). Pengaruh Kualitas Pelayanan Terhadap Kepuasan Dan Loyalitas Pasien Ditinjau Dari Persepktif Ekonomi Islam Pada RSUD Dr. H. Abdul Moeloek Provinsi Lampung (Doctoral dissertation, UIN Raden Intan Lampung).

Lubis, A.N. (2009). Gambaran Pengetahuan Tenaga Kesehatan Dengan Ketidak Lengkapan Isian Resume Medis Rawat Inap Di RS Hospital Cinere. 2009. Jakarta: Universitas Indonesia.

Herisa, D.C. (2017). Analisis Kelengkapan Rekam MEdis Rawat Inap Di Rumah Sakit Umum Rizki Amalia Kulon Progo Yogyakarta. 2017.

Erfavira, A., \& Kirana, S. (2012). Perbedaan Kelengkapan Pengisian Rekam Medis antara Instalasi Rawat Jalan dan Instalasi Rawat Darurat di Poli Bedah RSUP dr. Kariadi Semarang (Doctoral dissertation, Fakultas Kedokteran).

Hatta, G.R. (2011). Pedoman Manajemen Informasi Kesehatan di Sarana Pelayanan Kesehatan. Jakarta : Universitas Indonesia. 
Susanto, G. (2012). Sistem Informasi Rekam Medis Pada Rumah Sakit Umum Daerah (RSUD) Pacitan Berbasis Web Base. SpeedSentra Penelitian Engineering dan Edukasi, 3(4).

Dewi, F.D., \& Agustina, K. (2017). Analisis Sistem Pelayanan Rekam Medis Rawat Inap di RSUP Dr. Kariadi Semarang Tahun 2016. Jurnal Vokasi Indonesia, 5(2), p.2017.

Muyasaroh, D. (2016). FUNGSI MANAJEMEN PADA KEGIATAN PENGELOLAAN SISTEM REKAM MEDIS PASIEN DI PUSKESMAS KEDUNGMUNDU

SEMARANG (Doctoral dissertation, Universitas Negeri Semarang).

Indonesia, K.K. (2006). Manual Rekam Medis. Jakarta: Konsil Kedokteran Indonesia.

Ardika, R.G., \& Bhima, S.K.L. (2012). HUBUNGAN ANTARA PENGETAHUAN PERAWAT TENTANG REKAM MEDIS DENGAN KELENGKAPAN PENGISIAN CATATAN KEPERAWATAN: Di bangsal penyakit dalam RSUP Dr. Kariadi Semarang periode 1-31 Januari 2012 (Doctoral dissertation, Fakultas Kedokteran).

Lubis, E. (2009). Pengaruh Karakteristik Individu dan Motivasi Intrinsik terhadap Kinerja Dokter dalam Kelengkapan Pengisian Rekam Medis Pasien Rawat Inap di Rumah Sakit PT Perkebunan Nusantara IV (PERSERO) Tahun 2008. Universitas Sumatera Utara.

Istirochah. (2016). Analisis Kepatuhan Dokter Dalam Mengisi Rekam Medis di Rumah Sakit Umum Daerah Kabupaten Boyolali. (Doctoral dissertation, Universitas Muhammadyah Surakarta).
Eny, Y., \& Enny, R. (2008). Hubungan Pengetahuan Dokter Dengan Kelengkapan Dokumen Rekam Medis Rawat Jalan di Poliklinik Neurologi RSUP. Dr. Kariadi Semarang Oktober 2008. Jurnal Visikes, 3(2), pp.17-28.

Pratiwi A.H., Hariyanti T., \& Susilo S. (2015). Pengembangan Alur Pasien dan Berkas Rekam Medis sebagai Optimalisasi Sistem Informasi Rekam Medis. Jurnal kedokteran Brawijaya. 28(2):129-135.

Aditama, TY. (2000). Manajemen Administrasi Rumah Sakit. Jakarta: Penerbit Universitas Indonesia (UI-Press).

Fuanasari, A.D., Suparwati, A., \& Wigati, P.A. (2014). Analisis alur pelayanan dan antrian di loket pendaftaran pasien rawat jalan. Jurnal Kesehatan Masyarakat (e-Journal), 2(1), pp.15-21.

Notoatmojo, S. (2018). Metodologi Penelitian Kesehatan. Jakarta: Rineka Cipta.

Widjaya, L. (2018). Bahan Ajar Rekam Medis dan Informasi Kesehatan (RMIK) - Manajemen Mutu Informasi Kesehatan III "Pendokumentasian Rekam Medis" (I). Pusat Pendidikan Sumber Daya Manusia Kesehatan Badan Pengembangan dan Pemeberdayaan Sumber Daya Manusia Kesehatan Kementrian Kesehatan Republik Indonesia. 